\title{
Association of mast cells with helicobacter pylori infection in the antral mucosa
}

\author{
KC SR ${ }^{1}$, Amatya GL ${ }^{2}$
}

${ }^{1}$ Department of Pathology, KIST Medical College and Teaching Hospital, Lalitpur, Nepal

${ }^{2}$ Department of Gastroenterology, National Academy of Medical Sciences, Kathmandu, Nepal

\author{
Keywords: \\ Gastritis; \\ Mast Cell; \\ Helicobacter pylori
}

\begin{abstract}
Background: Helicobacter pylori infection is associated with mixed inflammatory cell infiltrate consisting of neutrophils, eosinophils, lymphocytes and plasma cells. Helicobacter pylori lead to mast cell degranulation and release of active chemical compounds in in-vitro conditions. The objective of this study was to find out the association of mast cell density and Helicobacter pylori in the antral mucosa of the stomach.
\end{abstract}

Materials and Methods: A total of 150 endoscopic biopsies were included in the study. In addition to routine Hematoxylin and Eosin stained slides, Giemsa stain was done in each case for the evaluation of Helicobacter pylori and mast cell density in the gastric mucosa.

Results: Out of 150 gastric biopsies with histopathological diagnosis of chronic gastritis, 36 cases (24\%) were positive for Helicobacter pylori. In the antral mucosa, mast cell density was significantly higher in the Helicobacter pylori-positive group than in the Helicobacter pylori-negative group $(\mathrm{P}<0.01)$.

Conclusion: Mast cells may play a role in the development of Helicobacter pylori gastritis.

\section{INTRODUCTION}

Mast cells are one of a numbers of inflammatory cells derived from bone marrow. It plays a role in the onset and regulation of inflammation. These cells mature within tissue, and contain cytoplasmic granules, which are involved in allergic reactions associated with Ig E. ${ }^{1,2}$ Mast cells store and release a number of chemical mediators such as heparin, histamine, eosinophilic chemotactic factor, and

\section{Correspondence:}

Dr. Shiva Raj K.C., MD

Department of Pathology, KIST Medical College, Lalitpur, Nepal

Email Address: shiva_kc_123@yahoo.com chondroitin sulfate, as well as prostaglandin D2, leukotriene C4, D4, E4, IL-4,5,6,8 and tumor necrosis factor.

Helicobacter pylori (H. pylori) infection elicits infiltration with neutrophils, eosinophils, lymphocytes and plasma cells. H. pylori or $\mathrm{H}$. pylori extracts lead to mast cell degranulation and to a release of active chemical compounds in in-vitro conditions. ${ }^{3}$

In this study we have assessed the relationship of mast cell density (MCD) to presence or absence of $\mathrm{H}$. Pylori. 


\section{MATERIALS AND METHODS}

A total of 150 patients, who had attended the Gastroenterology Endoscopy Unit of GRP Polyclinc, Kathmandu and had undergone endoscopy followed by biopsy. The specimens were fixed in $10 \%$ buffered formalin, processed, embedded in paraffin and cut in sequential 5 micrometer sections. One slide was stained by Hematoxylin and Eosin (H\&E) and other slide was stained by Giemsa stain. Detection of H. Pylori and mast cells counts were performed using a magnification of X400 in 5 different fields in both $\mathrm{H}$. pylori positive and $\mathrm{H}$. pylori negative cases. Mast cells were recognized by its numerous metachromatic cytoplasmic granules, which stained red-purple with the Giemsa stain. The counting areas included epithelium, lamina propria, and pits in various proportions. The data were analyzed using Statistical Package of Social Sciences (SPSS) version 17 for windows.

\section{RESULTS}

The mean age of the patients was 38 years ranging from 14 to 83 years. Out of these 150 cases $86(57.3 \%)$ were male and $64(42.7 \%)$ were female.

The mean numbers of mast cells per 5 Oil immersion field was of 5.066. In the antrum MCD was significantly higher in the H. pylori-positive than the H. pylori negative group $(\mathrm{P}<0.01)$. In $\mathrm{H}$. Pylori-positive cases the MCD was 9.00 where as in H. Pylori-negative cases it was 3.82. Comparison between MCD in relation to $\mathrm{H}$. Pylori is summarized in table 1.

\section{DISCUSSION}

Throughout the world, the rate of $\mathrm{H}$. pylori infection increases with age. ${ }^{4}$ In the stomach, it induces significant cellular and humoral immune responses via the antigenic stimulus of mucosal monocytes and T-lymphocytes. Various cytokines, proteases, prostaglandins, and reactive oxygen metabolites released from these inflammatory cells increase the endothelial adhesion of neutrophilic leukocytes. Local humoral mediators such as mucosal IgA lead to leukocyte accumulation, and the degranulation of eosinophilic leukocytes brings about the secretion of various cytokines, contributing to the progress of tissue damage. ${ }^{5,6}$

Table 1. Comparison between Helicobacter Pylori and Mast cell density

\begin{tabular}{lccccc}
\hline & \multicolumn{7}{c}{ Mast cell density(MCD)* } & \multirow{2}{*}{ Total } \\
& $2-4$ & $5-7$ & $8-10$ & $>10$ & \\
\hline Helicobacter Positive & 0 & 9 & 17 & 10 & 36 \\
Pylori Negative & 82 & 29 & 1 & 2 & 114 \\
\hline Total & 82 & 38 & 18 & 12 & 150 \\
\hline * Mast cell density per X400 in 5 fields (Giemsa stained slides)
\end{tabular}

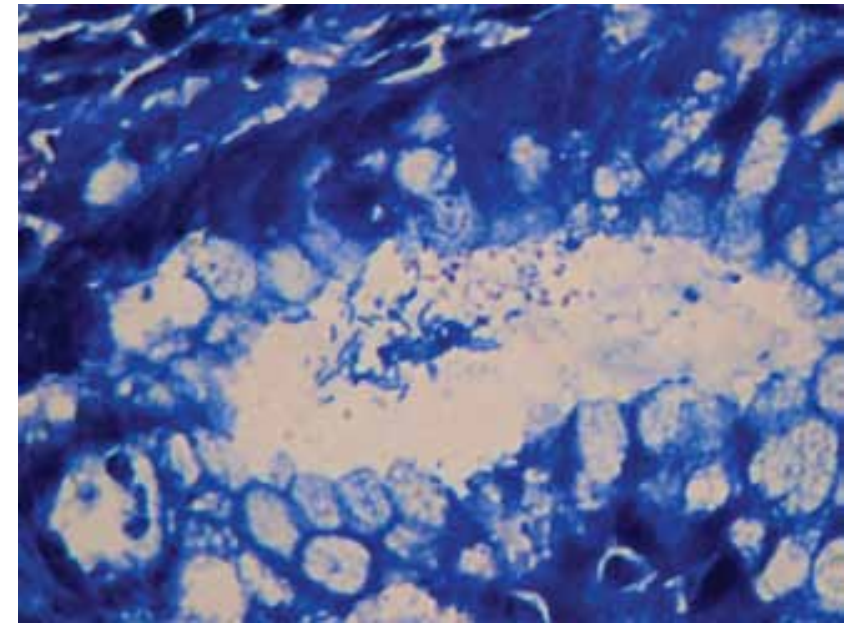

Figure 1: Photomicrograph showing H. Pylori in the gastric lumen (Giemsa Stain, X400)

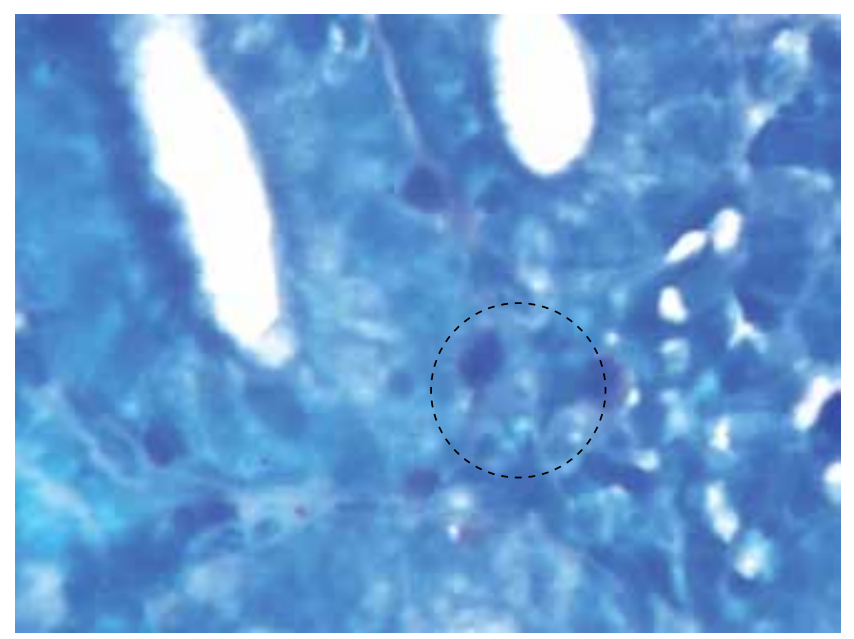

Figure 2: Photomicrograph showing Mast cells in the Lamina propria (Giemsa Stain, X400)

Mast cells are an important element in the cellular infiltration in the course of gastric mucosa inflammation with $\mathrm{H}$. pylori infection. ${ }^{7.8}$ It is recognized by its numerous metachromatic cytoplasmic granules, which range in size from 0.3 to $0.8 \mu \mathrm{m}$ and which may occupy the majority of the cell volume. These granules stain red-purple with Giemsa stain (fig. 1). This property of staining red upon application of a blue dye is referred to as metachromatic staining and is due to the presence of highly sulfated, anionic proteoglycans complexed with the various secretory granule proteases, a property that is shared by basophils. ${ }^{9}$ Mast cell detection is rather easy by a simple and inexpensive staining (Giemsa) which is also used to detect H. pylori (fig. 2). It is of worth noting that reliable detection is achieved by examining the tissue under oil immersion (x400). Although the gold standard is staining of tissue with anti-tryptase antibody by immunohistochemical methods, it is a time consuming and rather expensive method not recommended for routine pathologic assessment of gastric biopsies.

In chronic inflammatory intestinal illnesses the role of mast cells has not been completely explained. Studies have 
shown increased in mast cell count during the active phase of disease which supports continuous mast cell activity in these illnesses..$^{1,10,11}$ Nonetheless, the events initiating mast cell degranulation in the stomach or the colon are not completely clear. In addition to allergic stimuli, luminal invasive bacteria such as $\mathrm{H}$. pylori and neuropeptides can initiate degranulation with non-allergic stimuli. ${ }^{1}$

In our study, the MCD was higher in the gastric mucosa of patients with $\mathrm{H}$. Pylori positive gastritis. Similar finding was observed in the study of Nakajima et al. who demonstrated higher MCD in the gastric mucosa of patients with gastritis than in healthy subjects, and higher in patients with $\mathrm{H}$. pylori associated peptic ulcer disease than in those with gastritis. They also observed mast cell degranulation by electron microscope in patients with $\mathrm{H}$. pylori positive gastritis. ${ }^{11}$ In a number of clinical studies, mast cell density has been found to be different in H. pylori negative and positive cases of gastritis. ${ }^{5,6,12-15}$ The results of the present study are in agreement with the literature.

However, our data is not sufficient to comment on whether H. pylori affects MCD directly or whether the inflammation secondary to $\mathrm{H}$. pylori infection is responsible for the increase in gastric mucosa mast cell number since $\mathrm{H}$. pylori density is a well established factor in the severity of inflammation. We observed a significant correlation between $\mathrm{H}$. pylori and $\mathrm{MCD}$, in the antrum $(\mathrm{P}<0.01)$. This possibly suggests that the luminal binding of $\mathrm{H}$. pylori in mucosa may initiate mast cell degranulation by a non-allergic stimulus.

\section{CONCLUSION}

The result of the study suggests that mast cells play an important role in H. Pylori induced inflammation in the gastric mucosa.

\section{REFRENCES}

1. Saperas E. The role of mast cells in gastrointestinal inflammation. Gastroenterology 1996;110;1656-8.
2. Wershil BK, Furuta GT, Wang ZS, Galli SJ. Mast cell dependent neutrophil and mononuclear cell recruitment in immunoglobulin E-induced gastric reactions in mice. Gastroenterology 1996;110:148290.

3. Sulik A, Kemona A, Sulik M, Oldak E. Mast cells in chronic gastritis of children. Pol Merk Lek 2001;57: 156-60.

4. Fenoglio-Preiser CM, Noffsinger AE, Stemmermann GN. The nonneoplastic stomach disease, In: 2 ed. Gastrointestinal Pathology. Lippincott- Raven: Philadelphia; 1999. pp153-236.

5. Fazilet Kayaselçuk, Ender Serin, Yüksel Gümürdülü, Sema Bircan. Relationship between gastritis severity, Helicobacter pylori intensity and mast cell density in the antrum and corpus Turk J Gastroenterol 2002;13:154-8.

6. Mahjoub F, Hassanbeglou B, Pourpak Z, Farahmand F, Kashef N, Akhlaghi A: Mast cell density in gastric biopsies of pediatric age group and its relation to inflammation and presence of Helicobacter pylori. Diag Pathol 2007;2:14.

7. Supajatura V, Ushio $\mathrm{H}$, Wada $\mathrm{A}$ et al. Cutting edge: VacA, a vacuolating cytotoxin of Helicobacter pylori, directly activates mast cells for migration and production of proinflammatory cytokines. $\mathbf{J}$ Immunol 2002;168:2603-7.

8. Dixon MF, Genta RM, Yardley JH, Correa P. Classification and grading of gastritis. The updated Sydney System. International Workshop on the Histopathology of Gastritis. Am J Surg Pathol 1996;20:1161-81.

9. Strobel S, Miller HR, Ferguson A. Human intestinal mucosal mast cells: evaluation of fixing and staining techniques. J Clin Pathol 1981;34:851.

10. Beil WJ, Schulz M, McEuen AR et al. Number, fixation properties, dye-binding and protease expression of duodenal mast cells: comparisons between healthy subjects and patients with gastritis or Crohn's disease. Histochem J 1997;29:759-73.

11. Marshall JS. Repeated antigen challenge in rats induces a mucosal mast cell hyperplasia. Gastroenterology 1993;105;391-8.

12. Nakajima $\mathrm{S}, \mathrm{Krishnan} \mathrm{B}, \mathrm{Ota} \mathrm{H}$ et al. Mast cell involvement in gastritis with or without Helicobacter pylori infection. Gastroenterology 1997;113:746-54.

13. Santacroce L,Bufo P, Latorre V, Losacco T. Role of mast cells in the physiopathology of gastric lesions caused by Helicobacter pylori Chir Ital 2000;52:527-31.

14. Piazuelo MB, Camargo MC, Mera RM et al. Eosinophils and mast cells in chronic gastritis: possible implications in carcinogenesis Hum Pathol 2008;39:1360-69.

15. Mangham DC, Newbold KM. Mucosal mast cell in reflux gastritis and chronic (type B) gastritis. Histopathology 1989;15:531-5. 